\title{
Deformation Behavior in Cold-rolled Medium-Manganese TRIP steel and \\ Effect of Pre-strain on the Lüders Bands
}

\author{
Z.C. $\mathrm{Li}^{1,2}$, H. Ding ${ }^{1}$, R.D.K. Misra ${ }^{2}$, Z.H. Cai ${ }^{1}$
}

\begin{abstract}
$\underline{\text { Abstract }}$
Deformation behavior was studied in cold-rolled $0.2 \mathrm{C}-1.6 \mathrm{Al}-6.1 \mathrm{Mn}-\mathrm{Fe}$ transformation-induced plasticity (TRIP) steel subjected to intercritical annealing. The steel intercritically hardened at $650^{\circ} \mathrm{C}$ exhibited excellent mechanical properties, and the excellent ductility was primarily associated with the discontinuous TRIP effect. Moreover at $650^{\circ} \mathrm{C}$, the formation of Lüders bands was associated with TRIP effect and cooperative dislocation glide. The length of Lüders strain was gradually reduced with increasing pre-strain, and was eventually eliminated when the pre-strain was increased to $10 \%$. The increased average stability of retained austenite and increased dislocation density in ferrite induced by pre-strain was responsible for decrease and ultimate elimination of Lüders bands. While in steel intercritically annealed at $600^{\circ} \mathrm{C}$, ferrite and austenite was predominantly deformed, which was responsible for poor work hardening rate and inferior tensile properties.
\end{abstract}

Keywords: Austenite stability; deformation behavior; pre-strain; Lüders bands; TRIP steel; 


\section{Introduction}

Environmental concerns, high oil prices and increased safety standards are the driving forces behind the quest to develop advanced high-strength steels for automotive applications [1-2]. Recently, transformation induced plasticity (TRIP) light weight steels are being considered as a new class of high strength steels with exceptional formability [3-5]. Cold rolled TRIP steel sheets are good candidates for automotive applications. The TRIP effect derives from deformation-induced transformation of retained austenite to martensite [6]. This results in work hardening and hence delays the onset of necking, eventually leading to higher total elongation [7]. TRIP steels are characterized by enhanced ductility at very high strength [8], and the TRIP effect depends on the volume fraction and stability of retained austenite.

Many studies have been carried out on Fe-(5-7)Mn-(0.1-0.2)C (wt.\%) ternary alloy systems [9], and it was suggested that superior mechanical properties can be obtained with increase in $\mathrm{C}$ and $\mathrm{Mn}$-content, which increases the volume fraction of retained austenite. In 1972, Miller [10] reported Fe-5.5Mn-0.1C (wt.\%) steel with tensile strength of $878 \mathrm{MPa}$ and total elongation of 34\%. Luo et al. [11] reported Fe-5Mn-0.2C (wt.\%) steel with good combination of tensile strength of $850-950 \mathrm{MPa}$ and ductility of $20-30 \%$. Light weight steels generally consist of substitutional elements, such as aluminum and silicon, where their role is to optimize austenite stability by suppressing cementite formation [12]. Moreover, Al in TRIP steels encourages the growth of intercritical ferrite [13], which is a soft phase with good ductility and helps stabilize the austenite phase [14]. For the purpose of obtaining 
light weight steels with high strength-high ductility combination, Al is added to medium Mn TRIP steels.

The typical or "normal" mechanical behaviour of polycrystalline metallic materials in tensile tests is the smooth transition from elastic to elastic-plastic region with a steady increase in stress in the stress-strain curve, prior to necking. In contrast, materials exhibiting yield point phenomenon show an abrupt transition from elastic (or mainly elastic) state to elastic-plastic behavior, with drop in stress in the stress-strain curve. In majority of the cases, this drop in stress is accompanied by a region of almost constant nominal stress with some fluctuation. Within this region of nearly constant stress, plastic deformation takes place locally in deformation bands (generally referred as Lüders bands), starting at nucleation point and spreading out towards the unyielded part of the specimen. [15-18]. Formation of Lüders bands is a well known phenomenon in metallic materials, especially in low carbon steels, and has been well studied [19-20]. The presence of Lüders bands on the surface of the sheet during forming is undesirable. Thus, the identification of material and processing conditions for elimination of Lüders bands is important [21]. Lüders strain has been observed in stress-strain curves of intercritically annealed TRIP steel [6, 22-23], but the yield point phenomenon continues to be unclear. Furthermore, limited studies have been carried out to fundamentally understand and eliminate Lüders bands.

Yield strength, tensile strength, and strain hardening rate can be adjusted by processing methods such as pre-straining of austenitic TRIP-assisted steel [24]. The 
objective of study described here is to develop a scientific basis for eliminating Lüders bands by pre-straining in a low density Fe-0.2C-6.1Mn-1.6Al (wt.\%) TRIP steel. Additionally, the microstructural evolution and deformation behavior for different degree of pre-strain was studied to elucidate the relationship between deformation behavior and Lüders bands for different degree of pre-strain.

\section{Experimental}

The nominal chemical composition of the experimental steel was 0.2C-1.6Al-6Mn-Fe (wt.\%). A $40 \mathrm{~kg}$ experimental steel ingot was cast in a vacuum induction furnace. The ingot was heated at $1200^{\circ} \mathrm{C}$ for $2 \mathrm{~h}$, hot forged into rods of section size $100 \mathrm{~mm} \times 30 \mathrm{~mm}$, then air cooled to room temperature (RT). Subsequently, the rods were soaked at $1200^{\circ} \mathrm{C}$ for $2 \mathrm{~h}$, hot-rolled to $4 \mathrm{~mm}$ thick strip in the temperature range of $1150-850^{\circ} \mathrm{C}$, and finally air cooled to room temperature (RT). The as-hot-rolled strips were subsequently cold-rolled to $1 \mathrm{~mm}$ thickness.

To establish an appropriate heat treatment schedule, the intercritical temperature range was determined by dilatometry. Dilatometry samples were cylindrical specimens of diameter $3 \mathrm{~mm}$ and length $10 \mathrm{~mm}$. The dilatometric plot of the experimental steel is presented in Fig. 1a. After thermal expansion during the heating stage $\left(30-900{ }^{\circ} \mathrm{C}\right)$ at the rate of $20^{\circ} \mathrm{C} / \mathrm{s}$, the sample was held at $900^{\circ} \mathrm{C}$ for $3 \mathrm{~min}$. It is clear that no transformation took place in the sample during fast cooling, at the rate of $100^{\circ} \mathrm{C} / \mathrm{s}$, until martensite start (Ms) temperature. The intercritical temperature range of the experimental steel was $593-760{ }^{\circ} \mathrm{C}$. We recently [25-27] demonstrated that austenite reverted transformation (ART) annealing heat treatment (sample was 
subjected to accelerated cooling in water after austenitization, austenitization followed by intercritical annealing for a long time and finally air cooled to room temperature) used for medium Mn-content steels is not applicable to the experimental steel studied here. A long time annealing makes austenite too stable and weakens the TRIP effect. Thus, we adopted the approach of intercritical hardening of the cold rolled strips. Intercritical annealing was carried out at temperatures in the intercritical range $\left(600-750{ }^{\circ} \mathrm{C}\right.$ ) for $9 \mathrm{~min}$, followed by immediate quenching in water to room temperature (as shown in Fig. 1b).

Tensile specimens of dimensions $12.5 \mathrm{~mm}$ width and gage length of $25 \mathrm{~mm}$ were machined from the heat-treated sheets with tensile axis parallel to the prior rolling direction. Tensile tests were carried out at room temperature using a universal testing machine (SANSCMT5000) at a constant crosshead speed of $3 \mathrm{~mm} \cdot \mathrm{min}^{-1}$. Prior to the tensile tests, the uneven surface of the samples was polished. The samples were etched with $25 \%$ sodium bisulfite solution. The microstructure of the experimental steels prior to and after tensile deformation were examined using scanning electron microscope (SEM) and transmission electron microscope (TEM). The volume fraction of austenite was determined by X-ray diffraction (XRD) with $\mathrm{CuK}_{\alpha}$ radiation using direct comparison method [28], involving use of integrated intensities of (200) $)_{\alpha}$ and $(211)_{\alpha}$ peaks and those of $(200)_{\gamma},(220)_{\gamma}$ and $(311)_{\gamma}$ peaks. The volume fraction of austenite $\mathrm{V}_{\mathrm{A}}$ was calculated using equation [29]:

$V_{A}=1.4 I_{\gamma} /\left(I_{\alpha}+1.4 I_{\gamma}\right)$

where $I_{\gamma}$ is the integrated intensity of austenite and $I_{\alpha}$ is the integrated intensity of 
$\alpha$-phase.

\section{Results and discussion}

\subsection{Microstructure and mechanical properties}

The SEM micrographs of cold-rolled samples intercritically hardened in the temperature range of $600-700^{\circ} \mathrm{C}$ are presented in Fig. 2. Figs. $2 \mathrm{a}, 2 \mathrm{~b}$ and $2 \mathrm{c}$ describe the microstructure of samples quenched from $600{ }^{\circ} \mathrm{C}, 630^{\circ} \mathrm{C}$ and $650^{\circ} \mathrm{C}$, respectively. The microstructural constituents consisted of intercritical ferrite (F) and austenite (A) as the dominant phase. When the sample was quenched from $700^{\circ} \mathrm{C}$, as marked in Fig. $2 \mathrm{~d}$, the austenite was significantly decreased because of extensive martensitic (M) transformation.

The variation in the volume fraction of austenite obtained from XRD is summarized in Fig. 3. The austenite content in experimental steel increased from 44 vol.\% to 72 vol.\% with increase in intercritical hardening temperature from 600 to $650^{\circ} \mathrm{C}$, followed by a decrease to $25 \mathrm{vol} . \%$, when intercritical hardening was carried out at $700^{\circ} \mathrm{C}$ because of martensitic transformation. Thus, when the samples were heat-treated in the temperature range of $600-650^{\circ} \mathrm{C}$, the volume fraction of austenite increased with increase in temperature. With increase in temperature, the austenite stability decreases because of increase in austenite grain size. In the case of samples heat-treated in the temperature range of $700-750^{\circ} \mathrm{C}$, the higher the temperature, the more is the austenite transformed to martensite on quenching.

Engineering strain-stress plots of steel quenched from different temperatures are presented in Fig. 4a. It can be seen that the ultimate tensile strength (UTS) increased 
continuously with increase in intercritical temperature and the total elongation (TEL) decreased with increase in temperature after attaining a maximum value at $650^{\circ} \mathrm{C}$. In the case of samples intercritically hardened at $600^{\circ} \mathrm{C}$ (henceforth referred as sample 600) and $630^{\circ} \mathrm{C}$ (sample 630) exhibited low ductility. The reasons underlying the difference in ductility between the samples were elucidated by studying deformation mechanisms (see below).

\subsection{Deformation behavior and austenite stability}

The work-hardening behavior of the samples intercritically hardened at different temperatures is presented in Fig. 4b. Sample 650 exhibited three stages of work hardening rate $(\mathrm{WH})$ : in stage $1, \mathrm{WH}$ rapidly decreased, then increased with serrated behavior (stage 2), before rapidly decreasing again (stage 3) with increasing tensile strain. The majority of studies reported in the literature [30-32] primarily attribute the first stage to deformation of ferrite, the final stage is probably associated with deformation of ferrite and martensite as the martensitic transformation is inactive in this stage. The stage 2 characterized by an increase in work hardening rate with serrated behavior, is a consequence of TRIP effect accompanied by deformation of ferrite. In contrast, the WH of sample 600 was rapidly decreased. It is well known that austenite has superior deformability than ferrite. The austenite with high stability did not transform to martensite and deformed during tensile deformation. Thus, it is inferred that deformation of ferrite and austenite is the dominant deformation behavior in stage 1 of WH in sample 600. Dislocation movement in ferrite was also responsible for the decrease in WH in sample 600. Sample 630 also exhibited three stages of work 
hardening rate $(\mathrm{WH})$. But the strain corresponding to stage 2 was very small, which implied relatively poor TRIP effect.

Work hardening ability is expected to be influenced by austenite stability. It is known that the stability of austenite depends on factors including grain size and morphology of austenite $[33,34]$. With increase in temperature, the austenite stability decreases because of increase in austenite grain size (Fig. 2). In the attempt to quantify this behavior, equation (2) was used [35]:

$k \varepsilon=-\ln \left(\frac{f_{\gamma}}{f_{\gamma 0}}\right)$

In equation (2), $f_{\gamma 0}, f_{\gamma}$ and $k$ are initial austenite fraction, austenite fraction at strain $\varepsilon$, and the mechanical stability of austenite, respectively. A higher value of $k$ corresponds to lower austenite mechanical stability.

Sample $600(k=1.5)$ was comprised of 44 vol.\% austenite, and after tensile deformation to fracture, $12 \%$ of austenite was transformed to martensite, as shown in Fig. 3. The WH decreased rapidly and corresponded to a small strain region, which implied poor work hardening ability, where the low ductility is attributed to the deformation of ferrite and austenite and the weak TRIP effect contributed to low ductility. In contrast, sample $630(k=2.9)$ and sample $650(k=4.3)$ comprised of 56 and 72 vol.\% of austenite, respectively. The austenite transformation ratio of these two samples was $45 \%$ and $79 \%$, respectively, during tensile deformation. This implied that a higher transformation ratio of austenite-to-martensite led to larger strain corresponding to stage 2 of WH. As shown in Fig. 4b, stage 2 of WH in sample 650 significantly fluctuated, which is attributed to discontinuous TRIP effect involving 
stress relaxation and transfer during deformation, with consequent enhancement in ductility, as recently proposed by us [36, 37].

Based on the above discussion, it is suggested that the poor tensile properties of sample 600 is mainly because of deformation of ferrite and austenite. For sample 630, the ductility is attributed to a consequence of deformation of ferrite accompanied by the TRIP effect, while the softening effect of ferrite is slightly greater. In contrast, the excellent ductility of sample 650 is primarily associated with the discontinuous TRIP effect.

\subsection{Effect of pre-strain on Lüders bands}

The typical or "normal" mechanical behavior of polycrystalline metallic materials in tensile tests is the smooth transition from elastic to elastic-plastic region with a steady rise in stress-strain curve, before necking occurs. In contrast, materials exhibiting yield point phenomenon show an abrupt transition from elastic (or mainly elastic) state to elastic-plastic behavior, with a characteristic drop in stress in the stress-strain curve for sample 650, as shown in Fig. 5. The peak stress at the end of the elastic region is termed as the upper yield strength $R_{\mathrm{eH}}$ and the lowest stress level in the yield region is termed as the lower yield strength $R_{\mathrm{eL}}$. In majority of the cases, this drop in stress is followed by a region of nearly constant stress, and plastic deformation takes place locally in deformation bands (referred as Lüders bands) [15], starting at nucleation point and then spreads out towards the unyielded region of the specimen, as schematically described for a simplified case by points 1-3 in Fig. 5 . After the formation of plastic deformation band (or bands), the material shows typical 
strain-hardening behavior that is common to most other metallic materials $[15,38]$. These are undesirable features in applications where surface quality is vital, since the bands become visible on the finished component [16]. The occurrence of Lüders bands significantly affects material performance in load-bearing structural applications after yield stress [39]. Generally, the Lüders bands phenomenon is considered as an undesirable property for deep-drawing sheet steels, because it induces surface roughness in the sheets that are formed into complex shapes [39]. Thus, identifying specific materials processing condition for elimination of Lüders bands is very important.

The formation of Lüders bands is generally attributed to the dynamics of dislocation glide and is explained by Cottrell-Bilby theory [15-17, 40]. The upper and lower yield stresses occur with the dislocation glide and the onset of Lüders strain, respectively [16, 41]. Lüders strain occurs in the presence of austenite, which transforms to martensite. When appropriate combination of austenite and ferrite are subjected to tensile test, there is a strong dependence of Lüders strain on the stability of the austenite [16]. Lüders strain is also related to the volume fraction of retained austenite and its carbon concentration [20]. Austenite stability has a strong influence on Lüders strain [16-17]. Accordingly, we envisage that it should be possible to completely eliminate Lüders bands by increasing resistance to dislocation motion and optimizing the volume fraction and stability of austenite.

It is known that austenite is transformed into martensite during plastic deformation of TRIP steel. Thus, the volume fraction of retained austenite can be 
varied through pre-strain. Dislocation density varies with increase in strain during uniform deformation. Thus, the length of Lüders strain presumably changes with different degree of pre-strain. In this study, the characteristics of Lüders strain at different degree of pre-strain was analyzed. The engineering strain-stress plots of sample 650 at different degree of pre-strain are presented in Fig. 6a. It is clear that the length of the Lüders strain decreases with an increase in the degree of pre-strain. A set of two points (points A and B in Fig. 6b) were used to indicate the length of the Lüders strain as a function of different degree of pre-strain. On the basis of the experimental results, the following conclusions were drawn: As the amount of pre-strain increases from $0 \%$ to $3 \%$, the length of Lüders strain decreases from $18.3 \%$ to $12.2 \%$ strain. Similarily, the length of Lüders strain decreases from $12.2 \%$ to $8.1 \%$ strain, when the amount of pre-strain increases from $3 \%$ to $5 \%$. No Lüders strain was observed when the amount of pre-strain was increased to $10 \%$ (Fig. 6). Thus, Lüders strain decreases to a small extent, when the amount of pre-strain increases from $0 \%$ to $5 \%$, and Lüders bands are eliminated when the amount of pre-strain was increased to $10 \%$.

Work hardening (WH) rate plots obtained from the tensile test of sample 650 at different degree of pre-strains are presented in Fig. 7. All the plots exhibited three stages of $\mathrm{WH}$ rate. The increase in $\mathrm{WH}$ rate with the onset of stage 2 of $\mathrm{WH}$ rate is related to the occurrence of TRIP effect. The true strain corresponds to the initiation of TRIP effect for the three samples after $0 \%, 3 \%$ and $5 \%$ pre-strain was $2.79 \%, 3.19 \%$ and $3.85 \%$, respectively. The corresponding engineering strain was $2.83 \%, 3.24 \%$ and 
$3.92 \%$, respectively, which are similar to the strain corresponding to the initiation of Lüders bands for the three samples after 0\% (2.88\%), 3\% (3.28\%) and 5\% (3.99\%) pre-strain. Thus, Lüders strain form with the onset of TRIP effect. Lüders band formation is attributed to the dynamics of dislocation glide [15-17]. The theories of Cottrell-Bilby [40] and others are described in terms of locking of dislocations by solute atoms. Dislocations are pinned at the upper yield strength and break away, when the stress decreases to the lower yield stress. [15-17, 41]. Thus, in the case of sample 650, it can be deduced that stress decreases when the dislocations become mobile until the formation of Lüders bands. This is followed by a region of nearly constant stress, namely, formation of Lüders bands and is associated with TRIP effect and the cooperative dislocation glide.

Fig. 8 shows that the stress-strain curves overlapped with change in volume fraction of retained austenite and transformed martensite as a function of tensile strain in sample 650. It is intriguing that austenite essentially remains intact until the formation of Lüders bands, implying that majority of the induced transformation occurred within the localized deformation during the formation of Lüders band. This is an exceptional evidence given that the martensitic transformation during deformation is strain-induced because the stress alone has little influence on austenite in the region ahead of Lüders bands. Moreover, Lüders bands occur with the onset of the TRIP effect once austenite transforms to martensite. Compared with the samples after $3 \%$ and $5 \%$ pre-strain, it is clear that the volume fraction of retained austenite decreases sharply and transformed martensite increases in the sample after $10 \%$ 
pre-strain. Lüders bands is eliminated as the amount of pre-strain is increased to $10 \%$. Thus, the elimination of Lüders bands appears to be influenced by decrease in the volume fraction of retained austenite.

The microstructure of sample 650 after $0 \%$ and $10 \%$ pre-strain are presented in Fig. 9. It is apparent that after $10 \%$ pre-strain, approximately half of the austenite transformed to martensite. Furthermore, it is obvious that after $10 \%$ pre-strain, the grain size of the majority of the retained austenite was small. The austenite grain size is the critical factor in influencing austenite stability [36-37]. Thus, it is inferred that the retained austenite with relatively larger grain size has lower austenite stability and transforms to martensite more easily during tensile deformation. The proportion of austenite as a function of grain size in samples after $0 \%$ and $10 \%$ pre-strain are presented in Figs. 10a and 10b, respectively. The data is calculated by using the grid method. It is clear that the majority of austenite in the sample after $10 \%$ pre-strain was in the size range of $0.5-1 \mu \mathrm{m}$. In contrast, in sample with $0 \%$ pre-strain, the proportion of austenite in the grain size range of 0-0.5 $\mu \mathrm{m}, 0.5-1 \mu \mathrm{m}, 1-1.5 \mu \mathrm{m}, 1.5-2 \mu \mathrm{m}$ and 2 $\mu \mathrm{m}$ was $2.8 \%, 17.7 \%, 36.9 \%, 21.2 \%$ and $21.4 \%$, respectively. It is clear that austenite grain size in sample after $10 \%$ pre-strain was uniform and the average austenite grain size was smaller $(0.67 \mu \mathrm{m})$, while the austenite grain size in the sample after $0 \%$ pre-strain varied and the average austenite grain size was relatively larger $(1.35 \mu \mathrm{m})$. The austenite with different grain size resulted in different austenite stability, leading to the discontinuous TRIP effect in sample 650, which was discussed in our previous study [9]. 
It is reported that a single variant is preferred for deformation-induced martensite in an ultrafine-grained structure [42]. The mechanism of grain refinement-induced austenite stabilization can be discussed in the terms of the physical energy associated with austenite-to-martensitic transformation, involving Eqs. (3) and (4) as elucidated by Takaki et al. [43].

If austenite transforms to martensite via a single variant mode, the increase in elastic strain energy is given by [43-44]:

$\Delta E_{v} \quad=\quad 0.5 E_{1} \varepsilon_{1}^{2} \quad(x / d)^{2} \quad+\left(0.5 E_{2} \varepsilon_{2}^{2}+0.5 E_{3} \varepsilon_{3}^{2}\right) \quad(x / d)$

where $E$ and $\varepsilon$ are the Young's modulus and elastic strain in each lattice plane, $x$ is the thickness of martensite plate and lattice strain is elastically accommodated over the space of austenite grain (grain size: $d$ ). Inserting Young's modulus and strain in Eq. (3), the increase in elastic strain energy is [33]:

$\Delta E_{v}=1276.1(x / d)^{2}+562.6(x / d)$

Finally, an equation for the increase in elastic strain energy can be obtained as:

$\Delta E_{v}{ }^{\prime}=2552.2 x^{2}(1 / d)+562.6 x>0$

It can be seen that the value of $\Delta E_{v}$ increases with decrease in austenite grain size. For sample 650 after $0 \%$ pre-strain with average austenite grain size of $1.35 \mu \mathrm{m}, \Delta E_{v}$ is $\sim 277 \mathrm{MJ} / \mathrm{m}^{3}$ and for sample 650 after $10 \%$ pre-strain, $\Delta E_{v}$ increases significantly to $\sim 787 \mathrm{MJ} / \mathrm{m}^{3}$. Thus, the value of $\Delta E_{v}$ increases with decrease in average grain size of retained austenite, which decreases the ability to nucleate martensite and improves the average stability of retained austenite. Furthermore, the small-sized austenite with 
higher stability than large-sized austenite is also related to high C-content and more uniform distribution of $\mathrm{Mn}$, which was observed in our previous study [9, 36-37]. Thus, it is clear that the average stability of retained austenite is improved after $10 \%$ pre-strain. Austenite with larger grain size transforms to martensite earlier during the pre-strain, such that the average austenite grain size decreases with increase in the amount of pre-strain. Thus, it is inferred that the average stability of retained austenite increases with increase in the degree or amount of pre-strain. As shown in Fig. 6b, the engineering strain corresponds to the initiation of Lüders strain (point A) for the three samples after $0 \%, 3 \%$ and $5 \%$ pre-strain is $2.88 \%, 3.28 \%$ and $3.99 \%$, respectively. The increase in average stability of retained austenite delays the occurrence of TRIP effect and suppresses the initiation strain of Lüders bands, which results in decrease in Lüders strain. Thus, it is inferred that elimination of Lüders strain is associated with increase in the average stability of retained austenite induced by pre-straining.

The presence of a Lüders plateau in the stress-strain curve is usually associated with the absence of work hardening [45]. Observation of a Lüders plateau in the stress-strain curve is related to low work hardening rate. The stage 2 of work-hardening rate of sample 650 exhibited 2 stages of work hardening rate (WH) evolution (Fig. 7a): in stage I, corresponding to the Lüders strain, WH increased at initiation and then remained constant with fluctuation. While, WH increased sharply with the onset of stage II (true strain: 0.18), corresponding to the end of Lüders strain (engineering strain: 0.20). In stage II, the work hardening rate is greater than stage I. Thus, it is inferred that enhancing the work hardening rate can suppress the spread of 
Lüders bands. The high work hardening rate is likely to be due to high dislocation density. Dislocation evolution dominates the work-hardening rate during plastic deformation [45-46].

The evolution of dislocation density during deformation is generally described by dislocation creation/storage and dislocation annihilation. To describe dislocation evolution with strain, Bergstrom [47] proposed a simple one-parameter approach. A single variable, the average dislocation density, $\rho$ is used to describe the dislocation density-strain relationship, i.e. [48]:

$\rho=\left(\frac{\bar{m}}{b \cdot s \cdot \Omega}\right)\left(1-e^{-\Omega \varepsilon}\right)+\rho_{0} \cdot e^{-\Omega \varepsilon}$

$\frac{d \rho}{d \varepsilon}=\left(\rho_{0}-\frac{\bar{m}}{b \cdot s \cdot \Omega}\right) e^{-\Omega \varepsilon}$

where $\varepsilon$ is the strain, $\bar{m}$ is the Taylor constant, $s$ is the mean free path of dislocation motion, $b$ is the Burgers vector, $\Omega$ is the dynamic recovery coefficient [49] and $\rho_{0}$ is the density of dislocations at $\varepsilon=0$ ("grown-in" dislocations). It is clear that the average dislocation density increases with increase in tensile strain.

The outcome of the above equation is compared with the TEM micrographs. Bright-field TEM micrographs of sample 650 at different amount of pre-strain are presented in Fig. 11 in order to examine the dislocation evolution with increase in the amount of pre-strain. For sample 650 at $0 \%$ pre-strain, the microstructure consisted of a mixture of ferrite (F) and austenite (A) (Fig. 11a). A low density of dislocations was observed in ferrite and austenite resulted in low work hardening rate and larger Lüders strain. At $3 \%$ and $5 \%$ pre-strain, the density of dislocations in ferrite was increased. Furthermore, dislocations were present individually without extensive clustering, as 
shown in Figs. $11 \mathrm{~b}$ and $11 \mathrm{c}$. At $10 \%$ pre-strain, it can be seen that the density of dislocations in ferrite increased significantly and the dislocation density was high and dislocation sub-structure (cell structure) was formed. The density of dislocations in ferrite increased with increase in amount of pre-strain, whereas there was no such phenomenon in austenite. The density of dislocations in austenite barely changed with the increased amount of pre-strain. The explanation for this phenomenon is that austenite primarily transformed to martensite during tensile deformation, thus, it was easier for dislocation slip to occur in ferrite. According to the dislocation absorption theory [50], the dislocations in martensite moved into neighbouring soft ferrite. In other words, ferrite 'absorbed' dislocations from adjacent hard phase martensite.

The average dislocation densities in ferrite can be measured by X-ray diffraction (XRD) experiment [51-52]. The average dislocation density ( $\rho_{\mathrm{F}}$ for ferrite) were evaluated using X-ray diffraction profile. Selected diffraction of $(211)_{\alpha}$ was slowly scanned with a velocity of $0.2 \%$ min so as to obtain enough diffraction intensity and a good profile. The $(211)_{\alpha}$ peaks of sample 650 with different amount of pre-strain are presented in Fig. 12a, which clearly demonstrated the evolution of the peak profiles with pre-strain. The density of dislocations was calculated using equation (8) proposed by Dunn [53-54].

$\rho=\beta^{2} /\left(4.35 \times b^{2}\right)$

where $\rho$ and $\beta$ is dislocation density and half-width, respectively as determined by $\mathrm{X}$-ray diffraction profile, $b$ is Burgers vector and the value is $2.48 \times 10^{-8} \mathrm{~cm}$. Fig. $12 \mathrm{~b}$ summarizes the measured dislocation density in ferrite of sample 650 at different 
amount of pre-strain. It shows that with increase in amount of pre-strain, there was a continuous increase in the dislocation density in the ferrite grains. At $10 \%$ pre-strain, $\rho_{\mathrm{F}}$ increased sharply. This behavior is in agreement with TEM observations.

Finally, the evolution of microstructure and dislocation density of sample 650 with different amount of pre-strain is summarized. Fig. 13 shows schematic illustration of the change in microstructure and dislocation density in sample 650 with increase in pre-strain (from $0 \%$ to $10 \%$ ). With increase in pre-strain, the average grain size of retained austenite was decreased, which led to increased average stability of retained austenite, and dislocation density in ferrite was increased.

A set of two points (points A and B in Fig. 6b) were used to indicate the length of the Lüders strain. The true strain corresponds to points A and B at different amount of pre-strain are presented in Fig. 14. It is clear that the true strain corresponding to point A (onset of Lüders strain) increased with increasing pre-strain. This phenomenon is associated with increase in the average stability of retained austenite caused by pre-strain, which delays the occurrence of TRIP effect and suppresses the initiation strain of Lüders bands. Moreover, the true strain corresponding to point B (end of Lüders strain) decreased with increasing pre-strain. This is attributed to increased dislocation density in ferrite caused by pre-strain, which hinders dislocation slip and increases the work-hardening rate and rendered Lüders strain to end earlier. Based on the above discussion, it is clear that the strain of Lüders bands decreased with increasing amount of pre-strain. As a result, at $10 \%$ pre-strain, Lüders strain was eliminated because of greater average stability of retained austenite and increased 
dislocation density in ferrite.

\section{Conclusions}

The deformation behavior of samples intercritically hardened at different temperatures in cold-rolled $0.2 \mathrm{C}-1.6 \mathrm{Al}-6.1 \mathrm{Mn}-\mathrm{Fe}$ TRIP steel and the microstructural evolution and deformation behavior for sample 650 at different degree of pre-strain were studied in detail. The major findings of the study are as follows:

(1) The cold-rolled sample intercritically hardened at $650{ }^{\circ} \mathrm{C}$ exhibited excellent ductility, which was primarily associated with the discontinuous TRIP effect. Ferrite and austenite deformation was the dominant deformation behavior in sample 600 , which was responsible for poor work hardening rate and inferior tensile properties.

(2) In the case of sample 650, formation of Lüders bands was associated with TRIP effect and cooperative dislocation glide. The Lüders band formation was gradually reduced as the amount of pre-strain was increased from $0 \%$ to $5 \%$ and was eliminated as the amount of pre-strain was increased to $10 \%$.

(3) Pre-strain led to increase in the average stability of retained austenite, which delayed the occurrence of TRIP effect and suppressed the initiation strain of Lüders bands. The increased dislocation density in ferrite caused by pre-strain hindered dislocation slip and improved the work-hardening rate, which rendered Lüders strain to end earlier. Thus, the Lüders band formation was gradually decreased and eventually eliminated with the increase in degree of pre-strain.

\section{Acknowledgements}

The present study was financially supported by the National Natural Science 
Foundation of China (No: 51031001), National Science Foundation for Young Scientists of China (No: 51501035) and Chinese Postdoctoral Science Foundation (2015M580230 and 2016T90227). R.D.K.M. gratefully acknowledges support from National Science Foundation, USA through Grant \#DMR1602080.

\section{$\underline{\text { References }}$}

[1] E.V. Pereloma, K.F. Russell, M.K. Miller, I.B. Timokhina, Scripta Mater. 58 (2008) 1078-1081.

[2] L.J. Baker, S.R. Daniel, J.D. Parker, Mater. Sci. Technol. 18 (2002) 355-368.

[3] S. Lee, S.J. Lee, B.C. De Cooman, Scripta Mater. 65 (2011) 225-228.

[4] J. Shi, X.J. Sun, M.Q. Wang, W.J. Hui, H. Dong, W.Q. Cao, Scripta Mater. 63 (2010) 815-818.

[5] N. Nakada, K. Mizutani, T. Tsuchiyama, S. Takaki, Acta Mater. 65 (2014) 251-258.

[6] B.C. De Cooman, Curr. Opin. Solid State Mater. Sci. 8 (2004) 285-303.

[7] V.F. Zackay, E.R. Parker, D. Fahr, D.R. Bush, Trans. Am. Soc. Met. 60 (1967) 252-259.

[8] M.J. Santofimia, J.G. Speer, A.J. Clarke, L. Zhao, J. Sietsma, Acta Mater. 57 (2009) 4548-4557.

[9] Z.C. Li, H. Ding, Z.H. Cai, Mater. Sci. Eng. A. 639 (2015) 559-566.

[10] R.L. Miller, Metall Trans. 3A (1972) 905-912.

[11] H.W. Luo, J. Shi, C. Wang, W.Q. Cao, X.J. Sun, H. Dong, Acta Mater. 59 (2011) 4002-4008.

[12] T. Bhattacharyya, S.B. Singh, S. Das, A. Haldar, D. Bhattacharjee, Mater. Sci. Eng. A 528 (2011) 2394-2400.

[13] D.W. Suh, S.J. Park, C.S. Oh, S.J. Kim, Scripta Mater. 57 (2007) 1097-1100.

[14] Z.H. Cai, H. Ding, X. Xue, J. Jiang, Q.B. Xin, R.D.K. Misra, Scripta Mater. 68 (2013) 865-868.

[15] Rainer Schwab, Volker Ruff, Acta Mater. 61 (2013) 1798-1808.

[16] Joo Hyun Ryua, Jeong In Kima, Hyoung Seop Kimb, Chang-Seok Ohc, H.K.D.H. Bhadeshiaa, d, Dong-Woo Suh, Scripta Mater. 68 (2013) 933-936.

[17] Liming Fua, Zhiming Lia, Huanrong Wangb, Wei Wangb, Aidang Shan, Scripta Mater. 67 (2012) 297-300. 
[18] Geraldine Tan, Yinong Liu, Petr Sittner, Martin Saunders, Scripta Mater. 50 (2004) 193-198.

[19] E.O. Hall, Plenum Press, NY, USA, (1970) 1-126.

[20] E. Emadoddin, A. Akbarzadeh, G.H. Daneshi, Mater. Sci. Eng. A 447 (2007) 174-179.

[21] D.V. Wilson, P.S. Bate, Scripta Metall. 20 (1986) 1529-1533.

[22] Y. Sakuma, D.K. Matlock, G. Krauss, Metall. Trans. A 23A (1992) 1221-1232.

[23] S.J. Kim, C.G. Lee, T.H. Lee, C.S. Oh, Scripta Mater. 48 (2003) 539-544.

[24] Jeong-Hyeon Kim, Woong-Sup Park, Min-Sung Chun, Jong-Joo Kim, Jun-Hong Bae, Myung-Hyun Kim, Jae-Myung Lee, Mater. Sci. Eng. A. 543 (2012) 50-57.

[25] W.J. Dan, S.H. Li, W.G. Zhang, Z.Q. Lin, Mater. Design. 29 (2008) 604-612.

[26] W.Q. Cao, C. Wang, J. Shi, M.Q. Wang, W.J. Hui, H Dong, Mater. Sci. Eng. A 528 (2011) 6661-6666.

[27] G.B. Olson, M. Cohen, Metall Trans A, 6A (1975) 791-795.

[28] G.N. Haidemenopoulos, A.N. Vasilakos, J. Alloy. Compd 247 (1997) 128-133.

[29] B.K. Jha, Ram. Avtar, V. Sagar Dwivedi, Trans. Indian. Inst. Met. 49 (1996) 133-142.

[30] B.K. Jha, V. Ram Avtar, Sagar Dwivedi, V. Ramaswamy, J. Mater. Sci. Lett. 6 (1987) 891-893.

[31] W.J. Dan, S.H. Li, W.G. Zhang, Z.Q. Lin, Mater. Des. 29 (2008) 604-612.

[32] A. Arlazarov, M. Gouné, O. Bouaziz, A. Hazotte, G. Petitgand, P. Barges, Mater. Sci. Eng. A 542 (2012) 31-39.

[33] V.S.A. Challa, X.L. Wan, M.C. Somani, L.P. Karjalainen, R.D.K. Misra, Scripta Mater. 86 (2014) 60-63.

[34] R.D.K. Misra, P.K.C. Venkatsurya, M.C. Somani, L.P. Karjalainen, Metall. Mater. Trans. A 43A (2012) 5286-5297.

[35] K. Sugimoto, M. Kobayashi, S. Hashimoto, Metall. Mater. Trans. A 23A (1992) 3085-3091.

[36] Z.C. Li, R.D.K. Misra, Z.H. Cai, H.X. Li, H. Ding, Mater. Sci. Eng. A 673 (2016) 63-72.

[37] Z.C. Li, H. Ding, R.D.K. Misra, Z.H. Cai, H.X. Li, Mater. Sci. Eng. A. 672 (2016) 161-169.

[38] N, Tsuji, Y, Ito, Y, Saito, Y, Minamino, Scripta Mater. 47 (2002) 893-899.

[39] Jeong-Hyeon Kim, Woong-Sup Park, Min-Sung Chun, Jong-Joo Kim, Jun-Hong Bae, Myung-Hyun Kim, Jae-Myung Lee, Mater. Sci. Eng. A. 543 (2012) 50-57.

[40] A. H. Cottrell, B. A. Bilby, Proc. Phys. Soc. London 62A (1949) 49-56.

[41] W.G. Johnston, J.J. Gilman, J Appl Phys 30 (1959) 129-135.

[42] Y. Matsuoka, T. Iwasaki, N. Nakada, T. Tsuchiyama, S. Takaki, ISIJ Int. 53 (2013) 1224-1230.

[43] S. Takaki, K. Fukunaga, J. Syarif, T. Tsuchiyama, Mater. Trans. 45 (2004) 2245-2251.

[44] S. Yamamoto, K. Asabe, M. Nishiguchi, Y. Maebara, Tetsu-to-Hagane. 82 (1996) 771-775.

[45] S. Lee, S. J. Lee, S. S. Kumar, K. LEE, B.C. De Cooman, Metall. Mater. Trans. A 
42A (2011) 3638-3651.

[46] N. Jia, Z.H. Cong, X. Sun, S. Cheng, Z.H. Nie, Y. Ren, P.K. Liaw, Y.D. Wang, Acta Mater. 57 (2009) 3965-3977.

[47] Y. Bergström, H. Hallén, Mater. Sci. Eng. A. 55 (1982) 49-61.

[48] M. Li, L. Wang, J. D. Almer, Acta Mater. 76 (2014) 381-393.

[49] U.F. Kocksa, , H. Mecking, Prog Mater Sci 48 (2003) 171-273.

[50] K. Zhang, M. H. Zhang, Z. H. Guo, N. L. Chen, Y. H. Rong, Mater. Sci. Eng. A. 528 (2011) 8486-8491.

[51] Z.Y. Liang, Y.Z. Li, M.X. Huang, Scripta Mater. 112 (2016) 28-31.

[52] W. Li, W. Z. Xu, X. D. Wang, Y. H. Rong, Journal of Alloys and Comp. 474 (2009) 546-550.

[53] G. Dunn, E. F. Koch, Acta Mater. 5 (1957) 548-554.

[54] P Gay, P.B Hirsch, A Kelly, Acta Metall. 1 (1953) 315-319.

\section{$\underline{\text { Figure captions }}$}

Fig. 1. (a) Dilatometric curve showing intercritical temperature range and (b) heat treatment schedule for the experimental steel.

Fig. 2. SEM micrographs of samples intercritically hardened at different temperatures.

(a) $600^{\circ} \mathrm{C}$, (b) $630^{\circ} \mathrm{C}$, (c) $650^{\circ} \mathrm{C}$ and (d) $700^{\circ} \mathrm{C}$.

Fig. 3. Measured austenite fraction in undeformed and fractured samples heat-treated at different temperatures and transformation ratio of austenite.

Fig. 4. Engineering stress-strain curves and work hardening rate of samples intercritically hardened at different temperatures. (a) engineering stress-strain curves and (b) work hardening rate.

Fig. 5. Stress-strain behaviour of sample 650 and schematic of formation of plastic deformation band during the tensile test.

Fig. 6. (a) Engineering strain-stress plots and (b) comparison of length of Lüders strain in sample 650 at different degree of pre-strain. 
Fig. 7. Work hardening rate of sample 650 at different degree of pre-strain. (a) $0 \%$, (b) $3 \%,(\mathrm{c}) 5 \%$ and (d) $10 \%$.

Fig. 8. Engineering stress-strain curve and change in volume fraction of austenite and martensite during deformationin in sample 650. (a) change of austenite fraction and (b) change of martensite fraction.

Fig. 9. SEM micrographs of sample 650 at different degree of pre-strain: (a) $0 \%$ pre-strain and (b) $10 \%$ pre-strain.

Fig. 10. The proportion of austenite as a function of austenite size in sample 650 after (a) $0 \%$ of pre-strain and (b) $10 \%$ of pre-strain.

Fig. 11. TEM micrographs of sample 650 at different degree of pre-strain. (a) $0 \%$, (b) $3 \%$, (c) $5 \%$ and (d) $10 \%$. The insets are magnified of area marked by circles.

Fig. 12. (a) The (211) $\alpha$ peaks and (b) the dislocation density in sample 650 with different degree of pre-strain.

Fig. 13. Schematic sketch of evolution of microstructure and dislocation density in sample 650 at different degree of pre-strain. The gray, white and red phases show ferrite $(\mathrm{F})$, austenite (A) and transformed martensite $(\mathrm{M})$, respectively. The number of $(\perp)$ in gray phase qualitatively represents relative dislocation density in ferrite.

Fig. 14. The true strain corresponding to point A (onset of Lüders bands) and B (end of Lüders bands) in sample 650 as a function of the degree of pre-strain. 

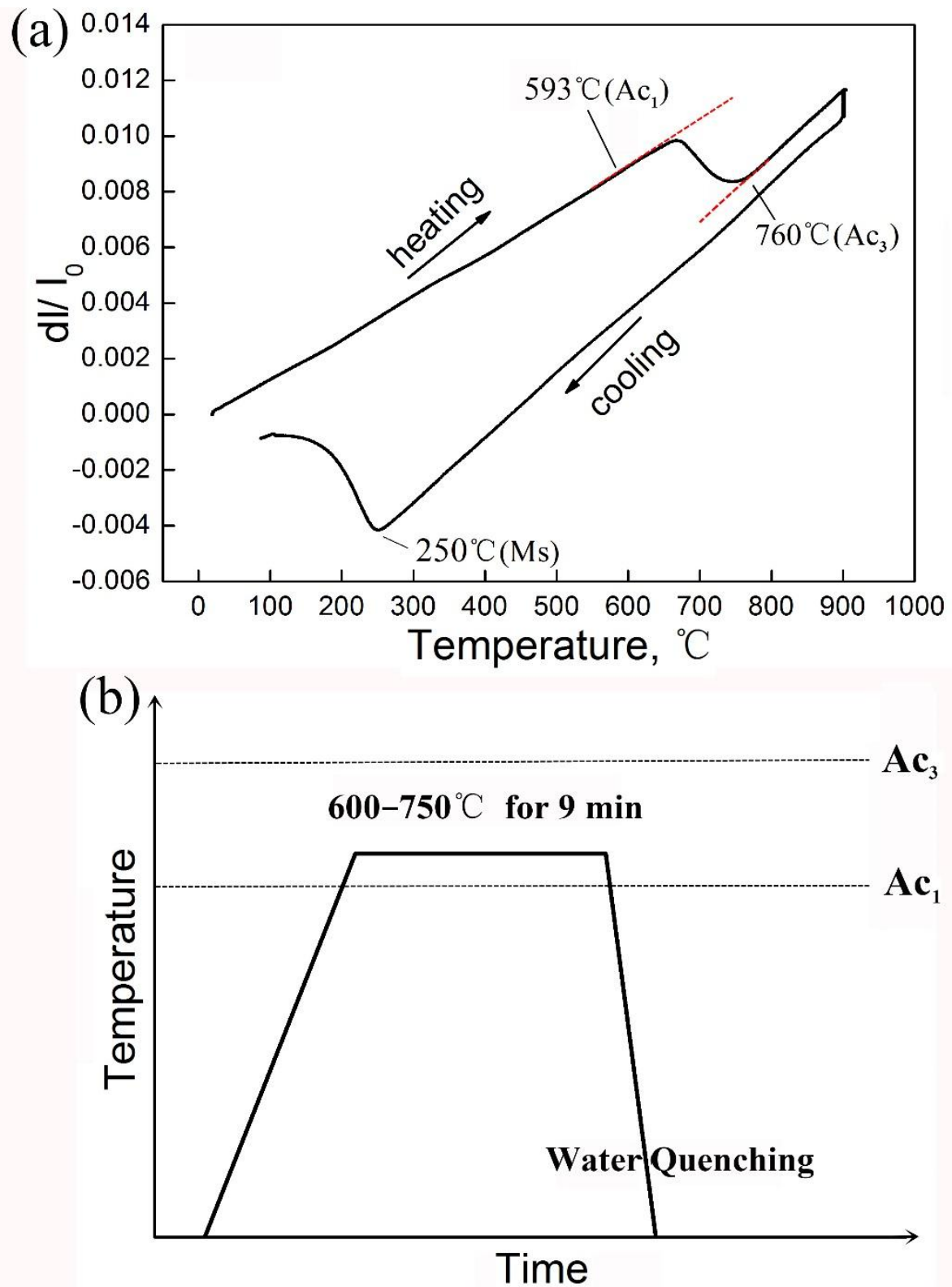

Fig. 1. (a) Dilatometric curve showing intercritical temperature range and (b) heat treatment schedule for the experimental steel. 

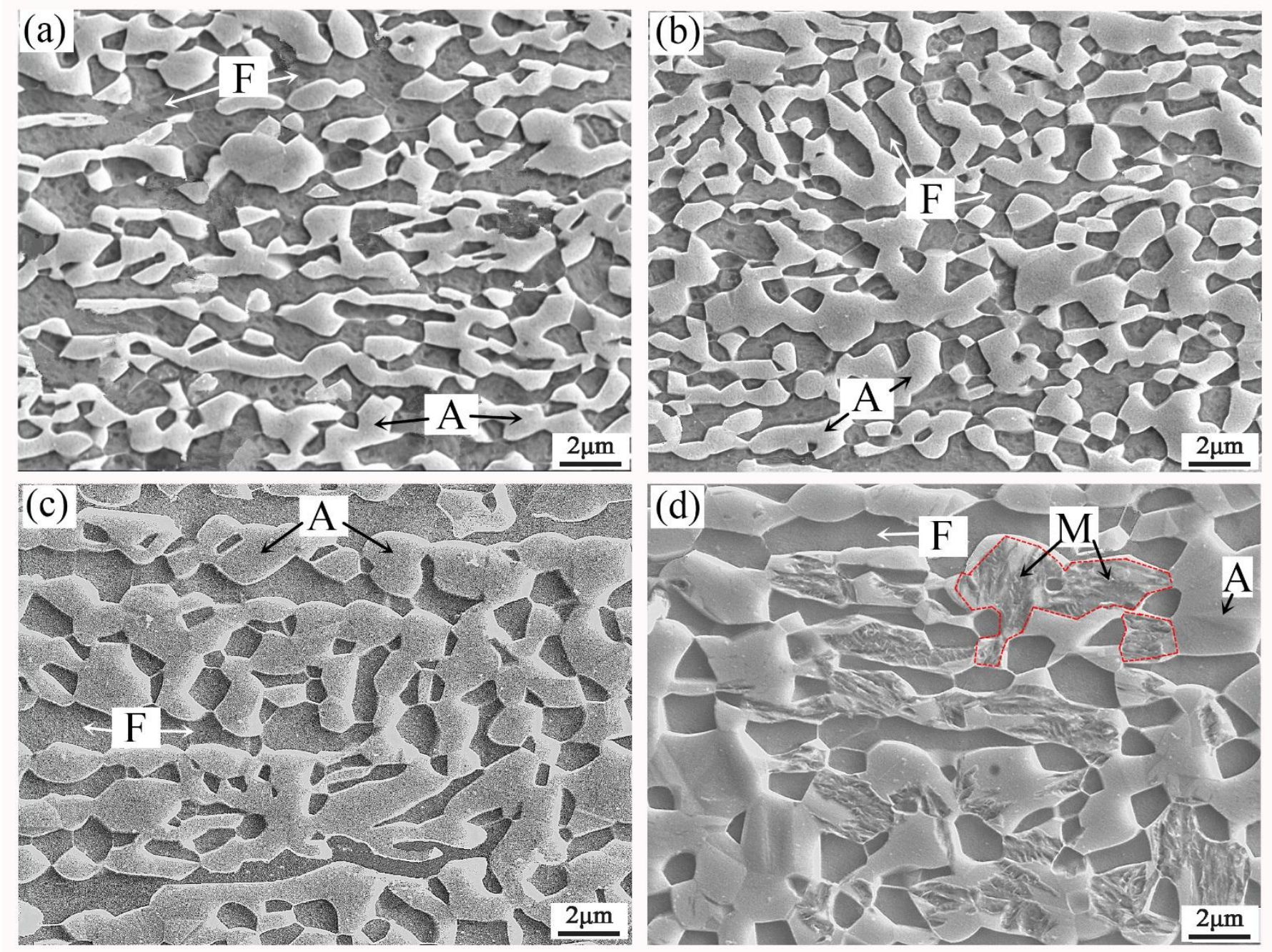

Fig. 2. SEM micrographs of samples intercritically hardened at different temperatures. (a) $600^{\circ} \mathrm{C}$, (b) $630^{\circ} \mathrm{C}$, (c) $650^{\circ} \mathrm{C}$ and (d) $700^{\circ} \mathrm{C}$. 


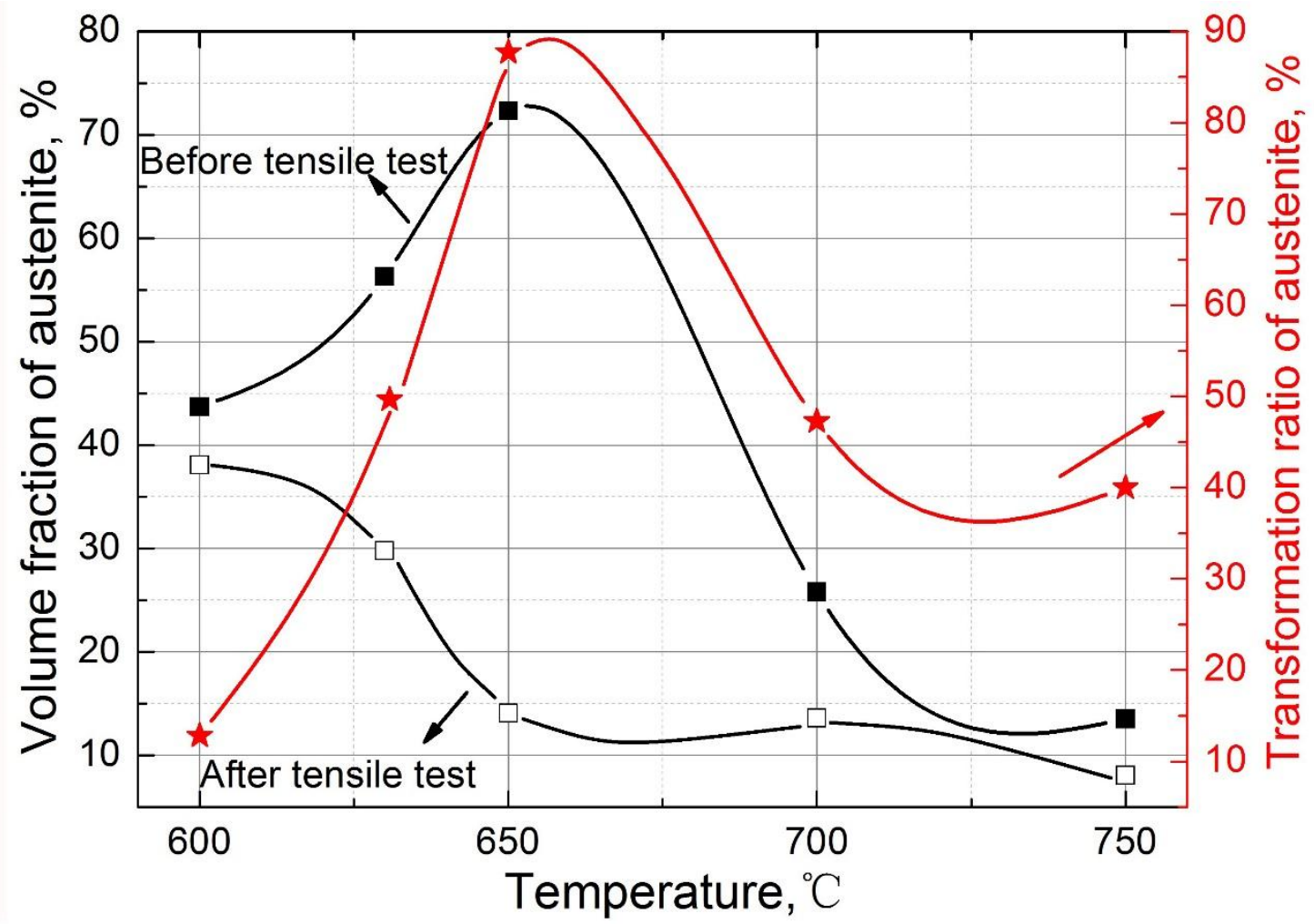

Fig. 3. Measured austenite fraction in undeformed and fractured samples heat-treated at different temperatures and transformation ratio of austenite. 

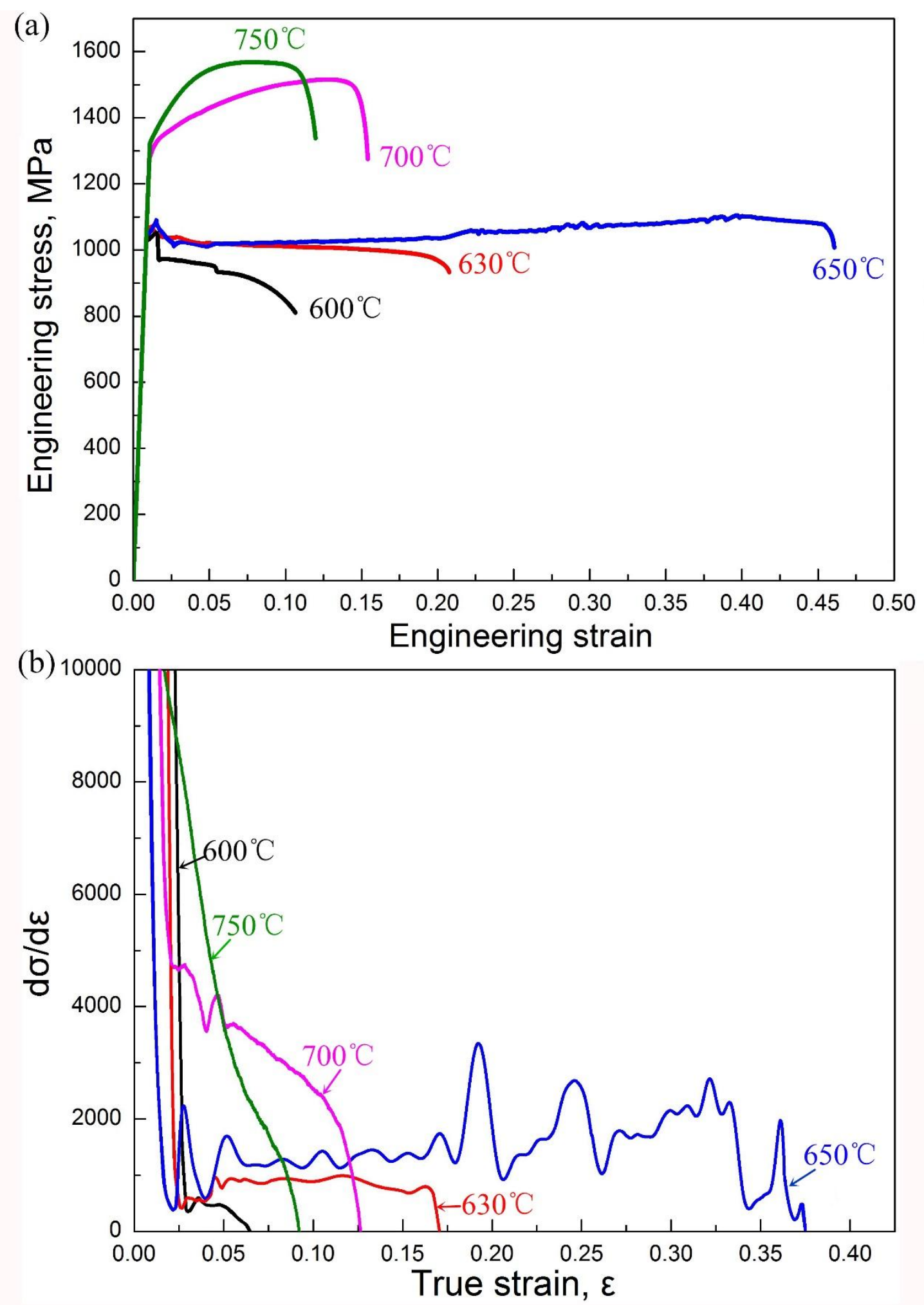

Fig. 4. Engineering stress-strain curves and work hardening rate of samples intercritically hardened at different temperatures. (a) engineering stress-strain curves and (b) work hardening rate. 


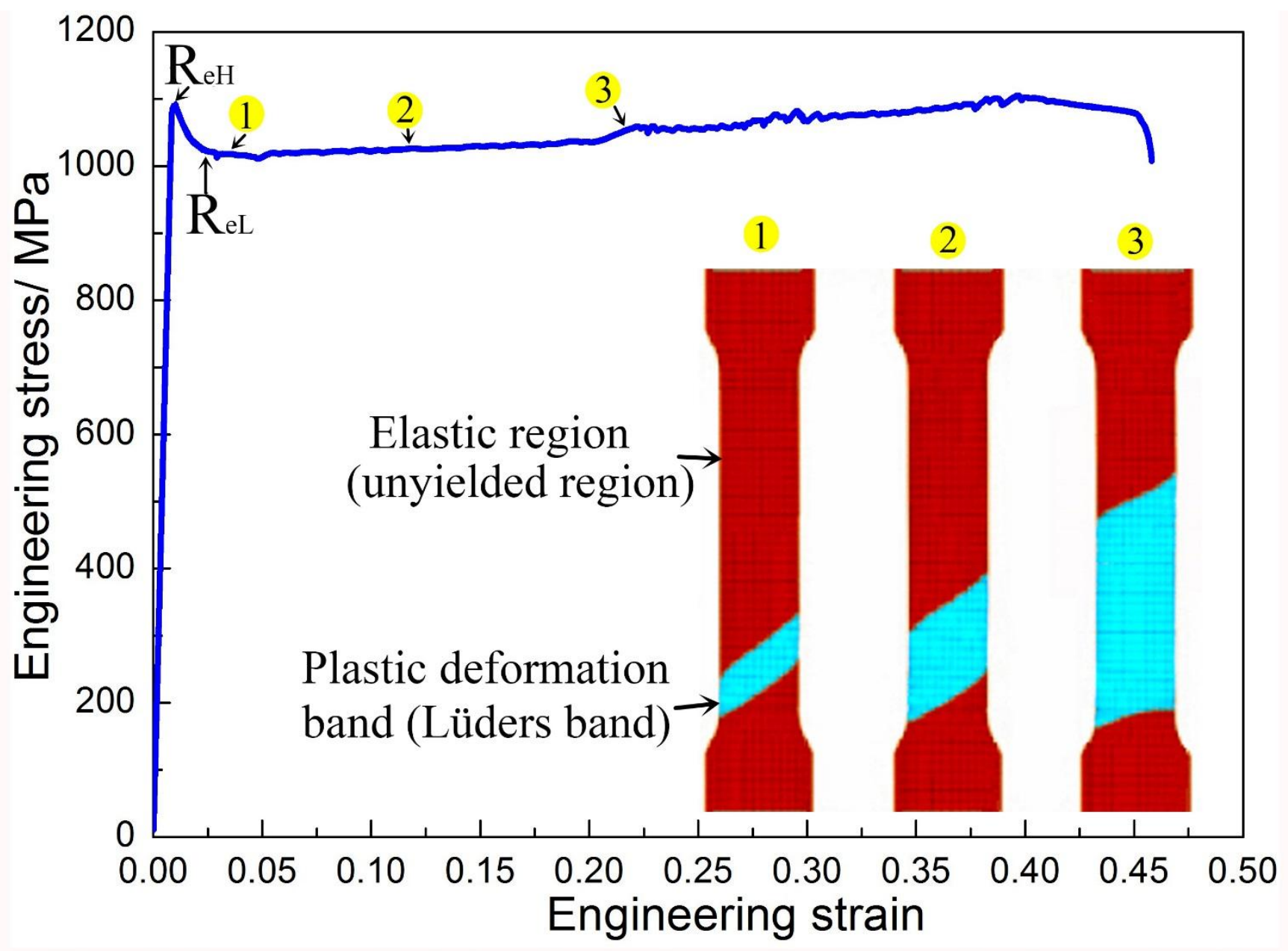

Fig. 5. Stress-strain behaviour of sample 650 and schematic of formation of plastic deformation band during the tensile test. 

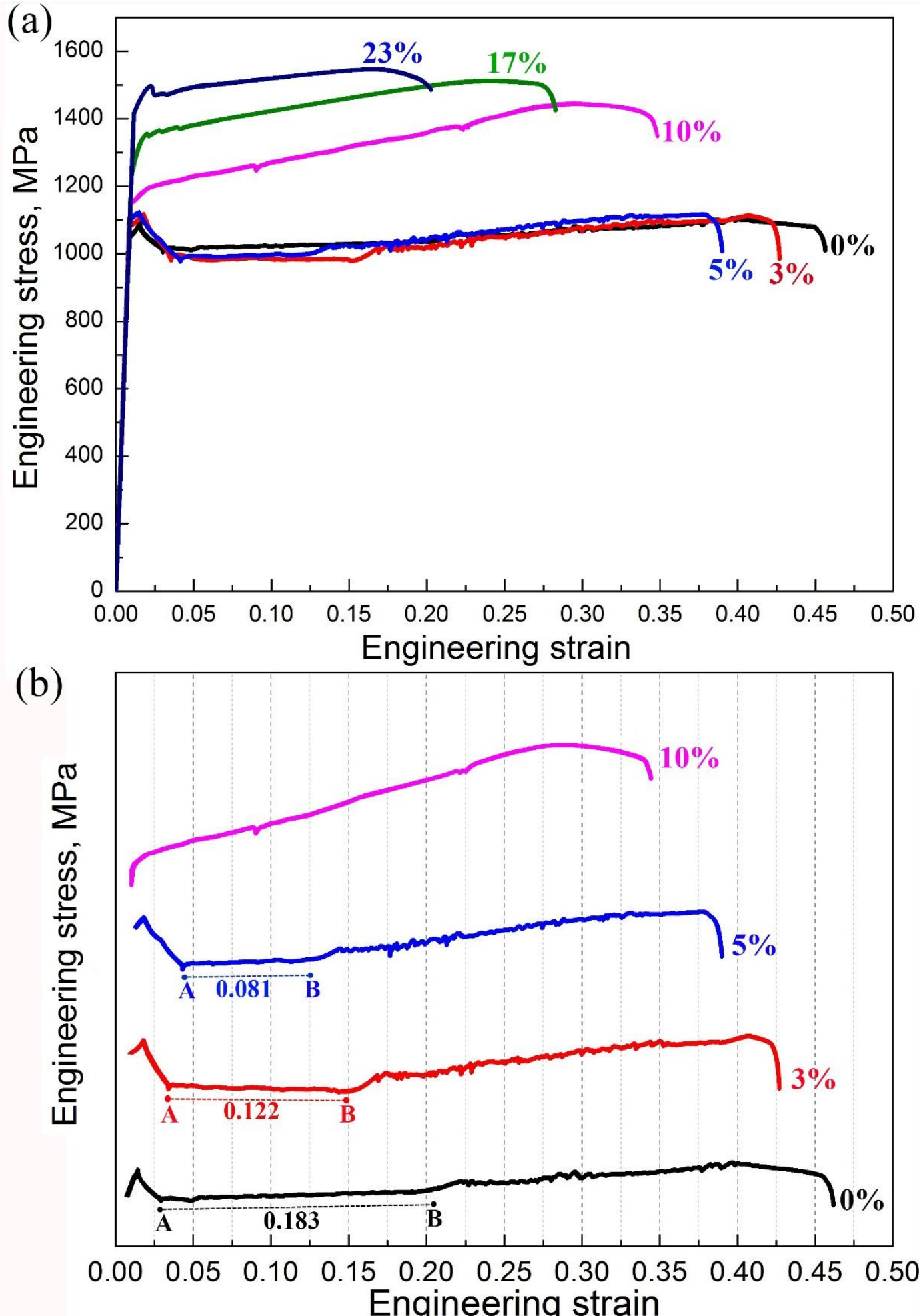

Fig. 6. (a) Engineering strain-stress plots and (b) comparison of length of Lüders strain in sample 650 at different degree of pre-strain. 

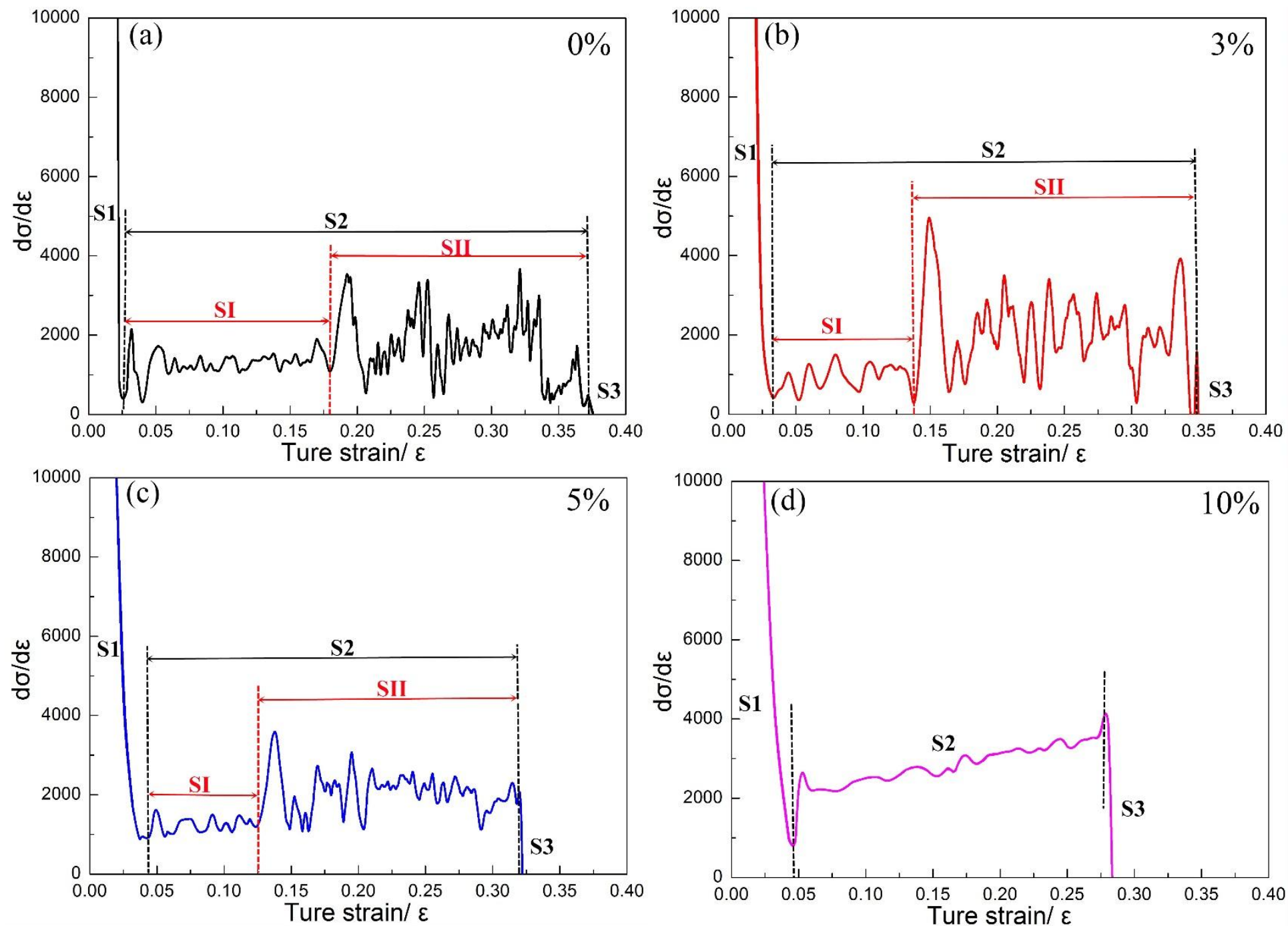

Fig. 7. Work hardening rate of sample 650 at different degree of pre-strain. (a) $0 \%$, (b) $3 \%$, (c) $5 \%$ and (d) $10 \%$. 

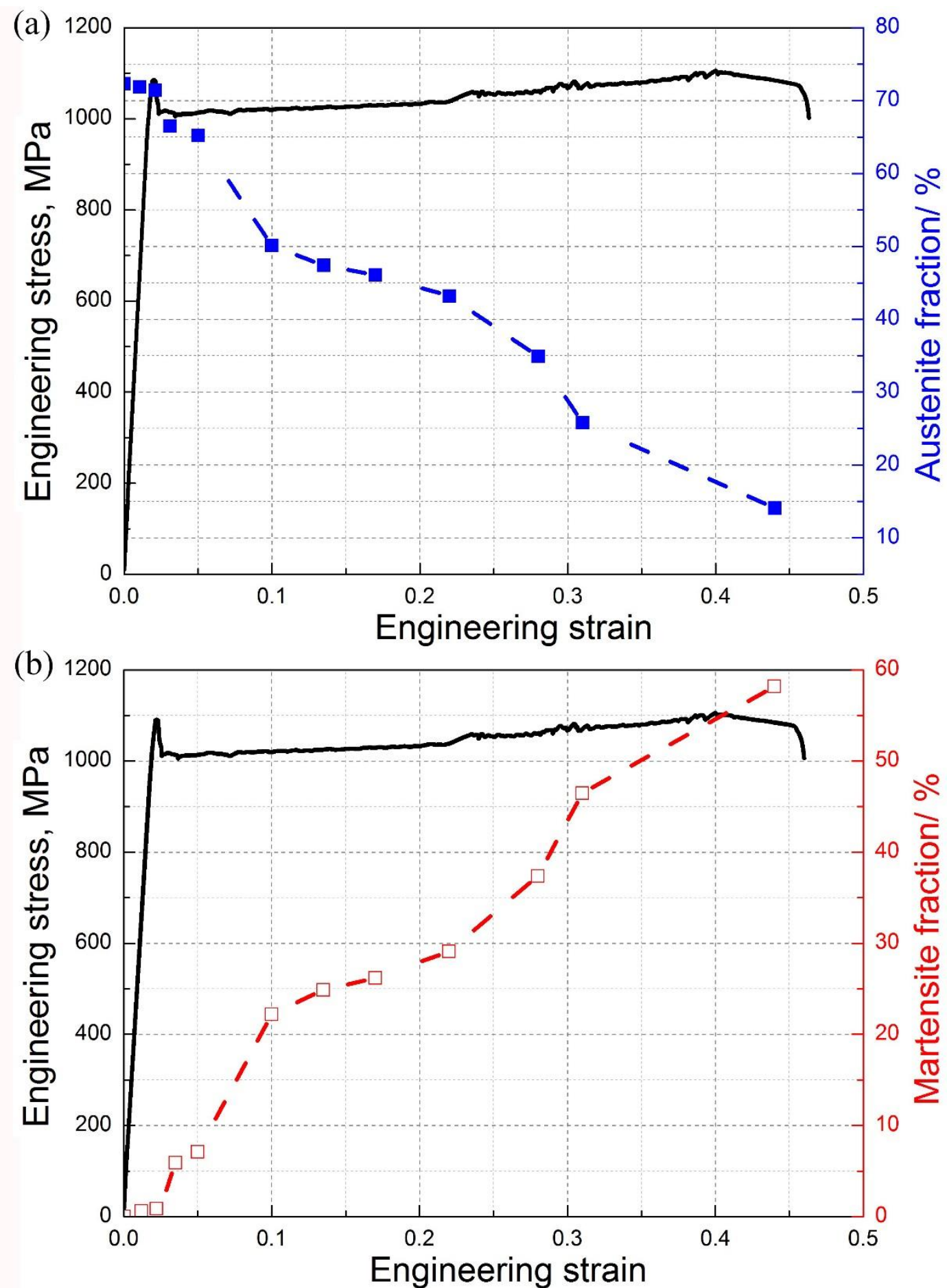

Fig. 8. Engineering stress-strain curve and change in volume fraction of austenite and martensite during deformationin in sample 650. (a) change of austenite fraction and (b) change of martensite fraction. 

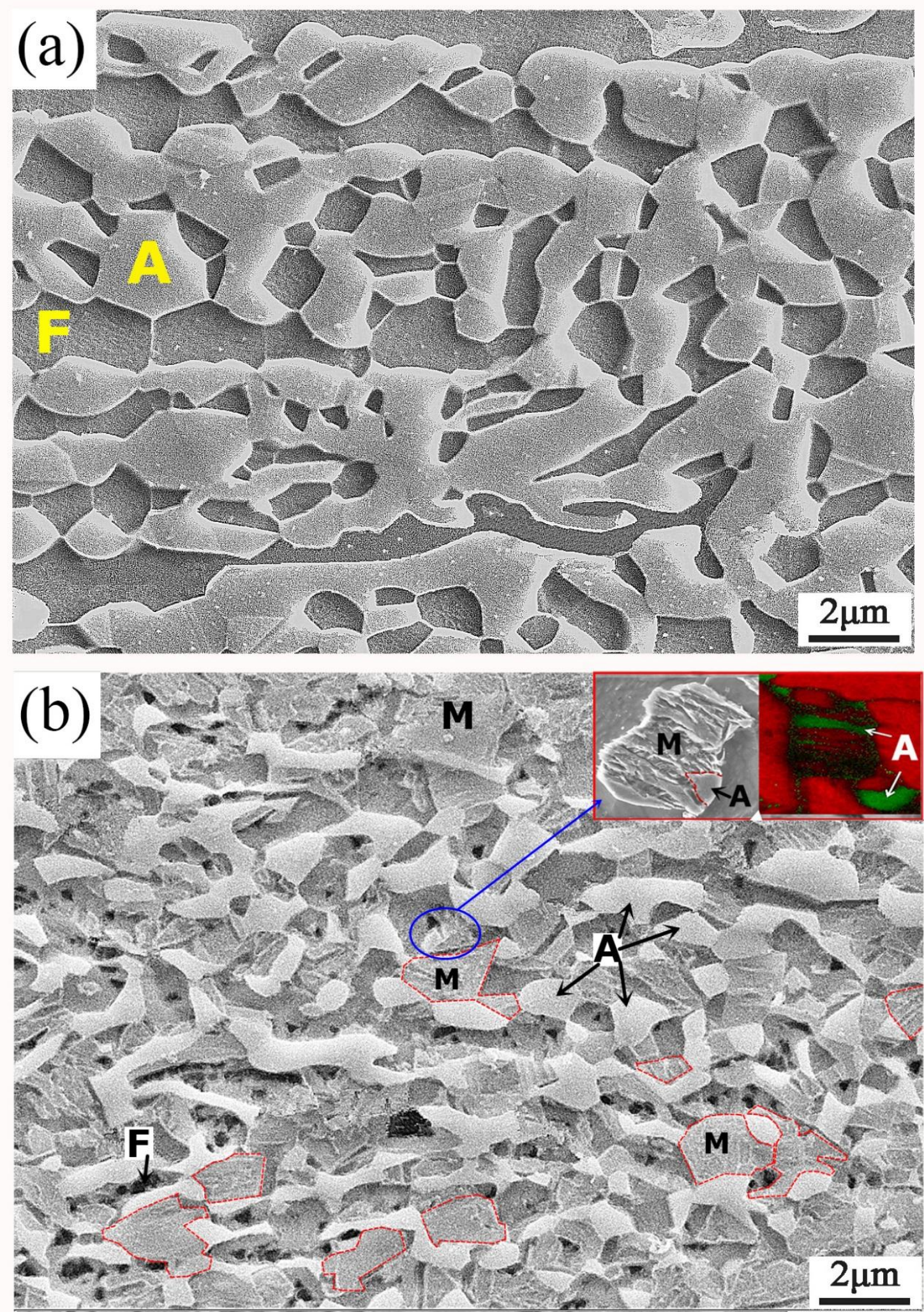

Fig. 9. SEM micrographs of sample 650 at different degree of pre-strain: (a) $0 \%$ pre-strain and (b) $10 \%$ pre-strain. 

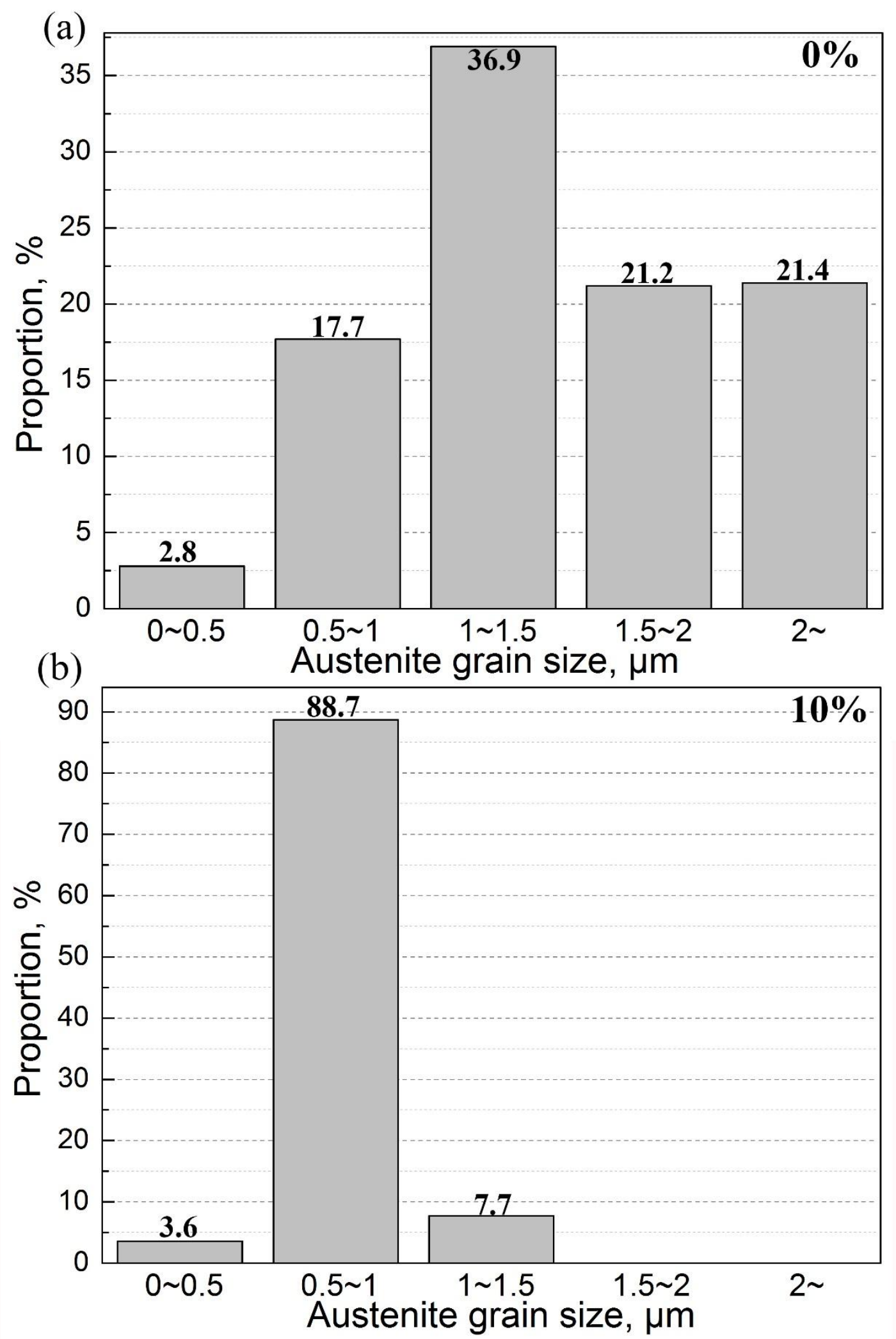

Fig. 10. The proportion of austenite as a function of austenite size in sample 650 after (a) $0 \%$ of pre-strain and (b) $10 \%$ of pre-strain. 

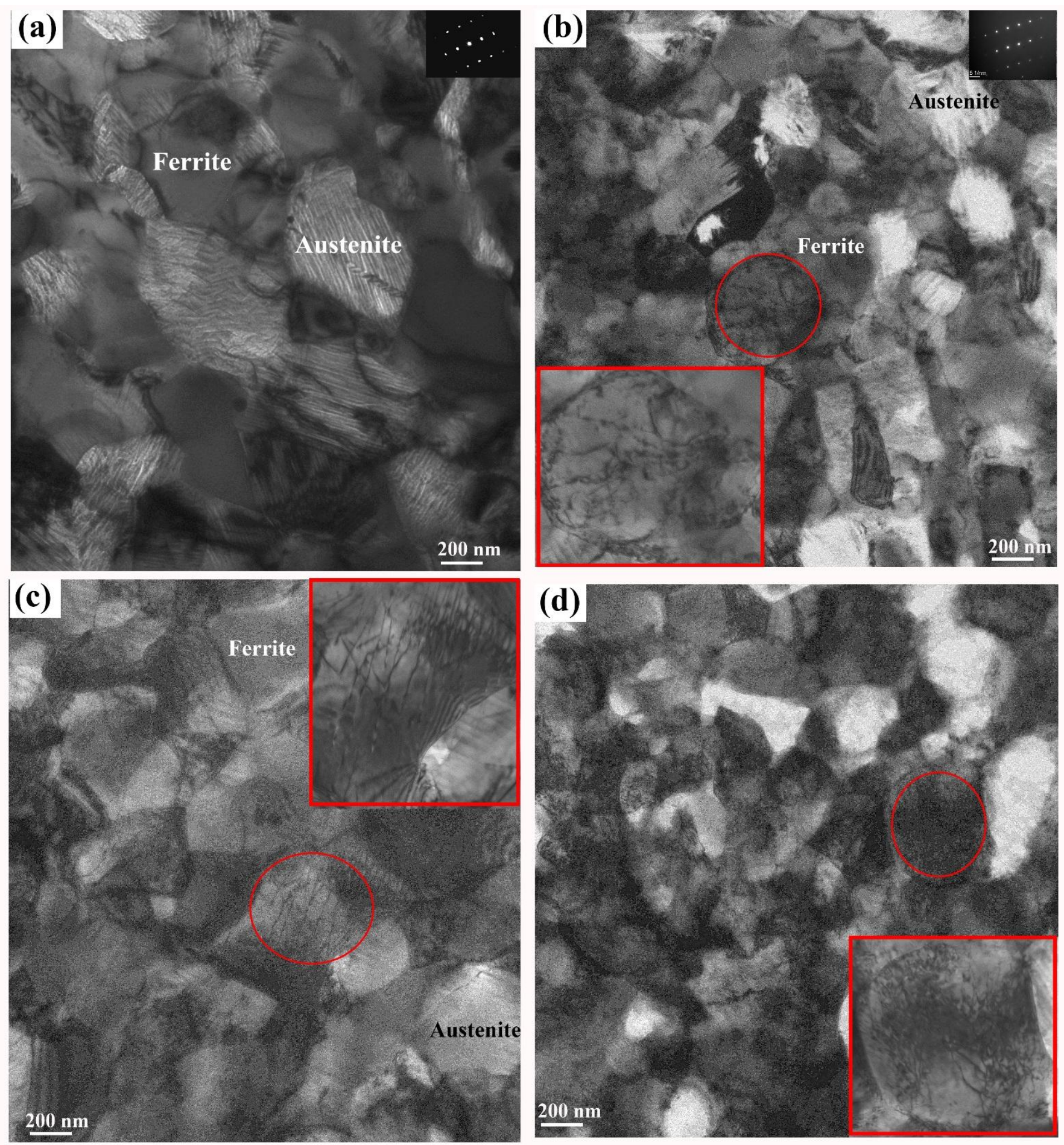

Fig. 11. TEM micrographs of sample 650 at different degree of pre-strain. (a) $0 \%$, (b) $3 \%$, (c) $5 \%$ and (d) $10 \%$. The insets are magnified of area marked by circles. 

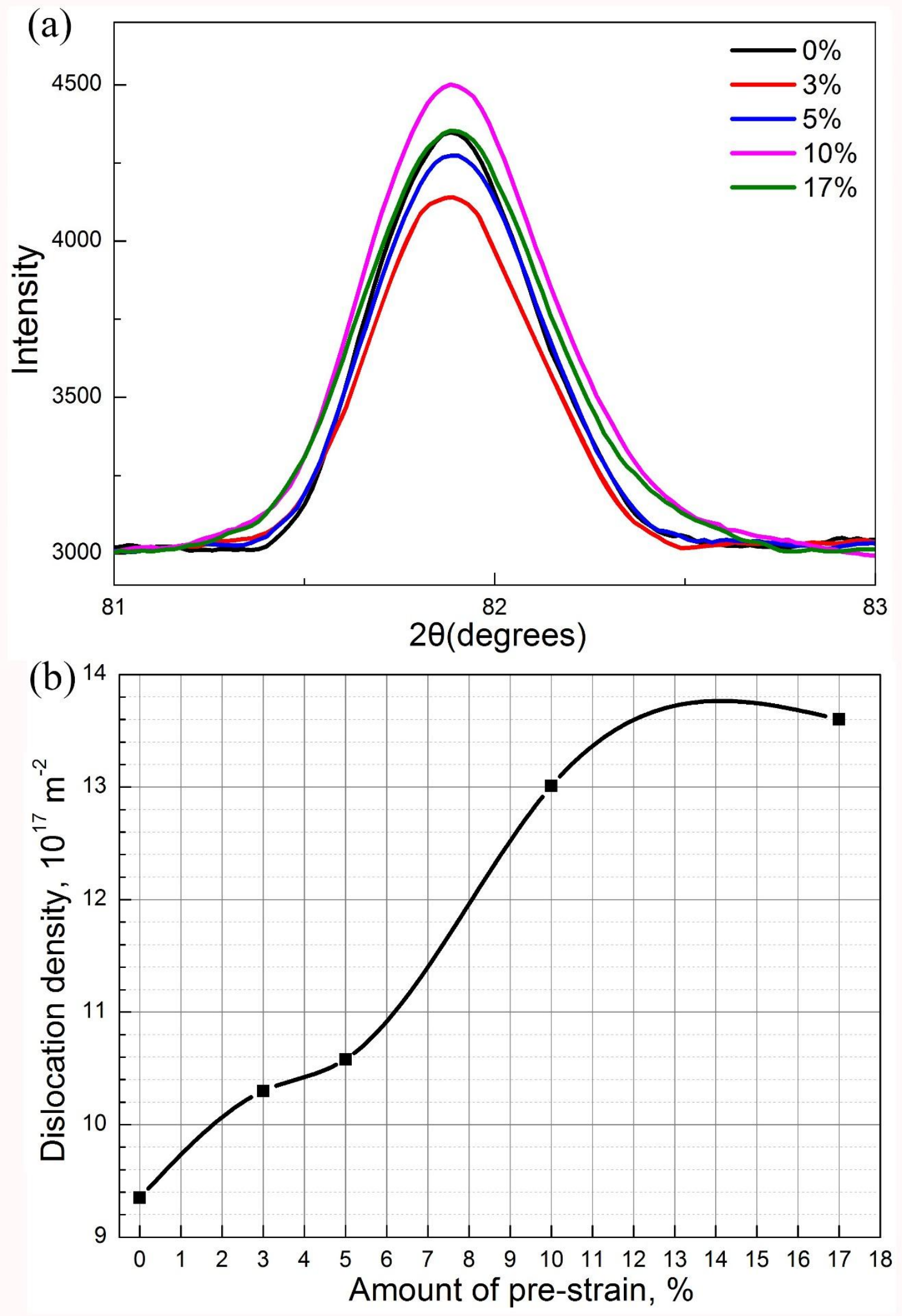

Fig. 12. (a) The (211) $\alpha$ peaks and (b) the dislocation density in sample 650 with different degree of pre-strain. 

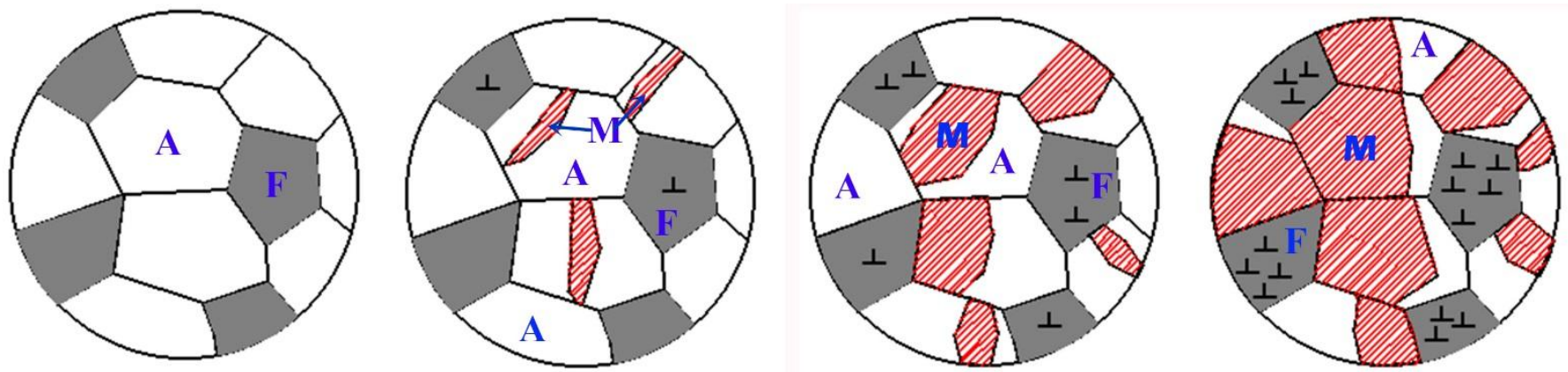

$$
0 \%
$$

Fig. 13. Schematic sketch of evolution of microstructure and dislocation density in sample 650 at different degree of pre-strain. The gray, white and red phases show ferrite (F), austenite (A) and transformed martensite $(\mathrm{M})$, respectively. The number of $(\perp)$ in gray phase qualitatively represents relative dislocation density in ferrite.

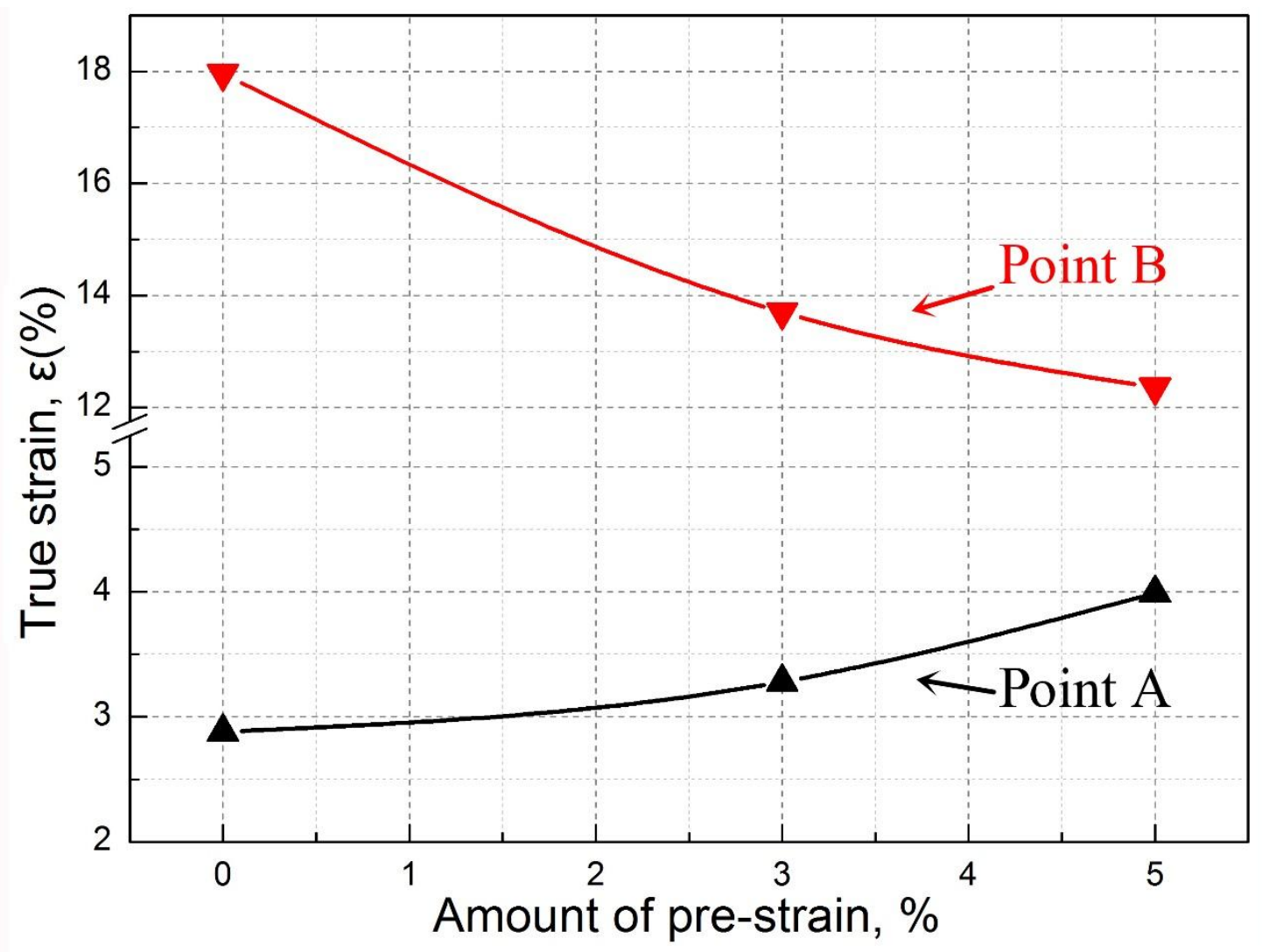

Fig. 14. The true strain corresponding to point $A$ (onset of Lüders bands) and $B$ (end of Lüders bands) in sample 650 as a function of the degree of pre-strain. 